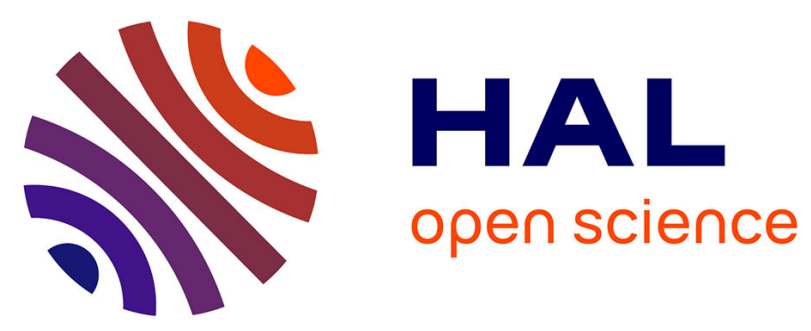

\title{
Heat exposure and socio-economic vulnerability as synergistic factors in heat-wave-related mortality
}

Grégoire Rey, Anne Fouillet, Pierre Bessemoulin, Philippe Frayssinet, Anne Dufour, Eric Jougla, Denis Hémon

\section{- To cite this version:}

Grégoire Rey, Anne Fouillet, Pierre Bessemoulin, Philippe Frayssinet, Anne Dufour, et al.. Heat exposure and socio-economic vulnerability as synergistic factors in heat-wave-related mortality. European Journal of Epidemiology, 2009, 24 (9), pp.495-502. 10.1007/s10654-009-9374-3 . inserm-03244738

\section{HAL Id: inserm-03244738 https://www.hal.inserm.fr/inserm-03244738}

Submitted on 1 Jun 2021

HAL is a multi-disciplinary open access archive for the deposit and dissemination of scientific research documents, whether they are published or not. The documents may come from teaching and research institutions in France or abroad, or from public or private research centers.
L'archive ouverte pluridisciplinaire $\mathbf{H A L}$, est destinée au dépôt et à la diffusion de documents scientifiques de niveau recherche, publiés ou non, émanant des établissements d'enseignement et de recherche français ou étrangers, des laboratoires publics ou privés. 


\section{Heat exposure and socio-economic vulnerability as}

\section{synergistic factors in heat-wave-related mortality}

\section{Authors:}

Grégoire Rey ${ }^{1,2,3}$, Anne Fouillet ${ }^{1,2}$, Pierre Bessemoulin ${ }^{4}$, Philippe Frayssinet ${ }^{4}$, Anne Dufour ${ }^{5}$, Eric Jougla $^{3}$, Denis Hémon ${ }^{1,2}$

${ }^{1}$ INSERM, U754, Villejuif, France

${ }^{2}$ Univ Paris-Sud, UMR-S754, IFR69, Villejuif, France

${ }^{3}$ INSERM, CépiDc, Centre d'Epidémiologie sur les Causes Médicales de Décès, Le Vésinet, France ${ }^{4}$ Meteo-France, Toulouse, France

${ }^{5} \mathrm{CNRM}$, Toulouse, France

\section{Corresponding Author:}

Grégoire REY

Inserm-CépiDc

44, Chemin de Ronde

F-78116 Le Vésinet Cedex, France

e-mail: Gregoire.Rey@inserm.fr

tel.: (+33) 134802432 fax: (+33) 134802429 


\section{ABSTRACT}

Background Heat waves may become a serious threat to the health and safety of people who currently live in temperate climates. It was therefore of interest to investigate whether more deprived populations are more vulnerable to heat waves. Methods In order to address the question on a fine geographical scale, the spatial heterogeneity of the excess mortality in France associated with the European heat wave of August 2003 was analysed. A deprivation index and a heat exposure index were used jointly to describe the heterogeneity on the Canton scale (3706 spatial units). Results During the heat wave period, the heat exposure index explained $68 \%$ of the extra-Poisson spatial variability of the heat wave mortality ratios. The heat exposure index was greater in the most urbanized areas. For the three upper quintiles of heat exposure in the densely populated Paris area, excess mortality rates were two-fold higher in the most deprived Cantons (about 20 excess deaths/100 000 people/day) than in the least deprived Cantons (about 10 excess deaths/100 000 people/day). No such interaction was observed for the rest of France, which was less exposed to heat and less heterogeneous in terms of deprivation. Conclusion Although a marked increase in mortality was associated with heat wave exposure for all degrees of deprivation, deprivation appears to be a vulnerability factor with respect to heat-wave-associated mortality.

Keywords: Heat Wave, Mortality, Vulnerability, Ecological study, Deprivation Abbreviations:

HEl: heat exposure index

HW-MR: heat wave mortality ratio

SEMR: standardized excess mortality rate

UUC: urban unit category 


\section{INTRODUCTION}

In the context of climate change, an increased frequency of extreme weather events is expected, with little uncertainty, within decades.[1] During summer 2003, very high temperatures were recorded over the whole of Western Europe.[2] In France, from $3^{\text {rd }}$ to $15^{\text {th }}$ August, the heat wave was associated with an excess mortality of nearly 14000 deaths.[3] It is therefore important to determine whether more deprived populations are more vulnerable to heat waves.

Case-control studies have been used by various authors to compare the subjects who died during a heat wave and/or were considered to have died because of the heat to survivors of the same heat wave.[4-6] However, except for some very specific variables such as the presence of air conditioning or living on the top floor, such studies did not enable vulnerability to heat to be distinguished from that associated with general mortality.

In a temporal analysis of the time course of mortality in seven US cities, a greater increase in heatrelated mortality was observed for low socio-economic level subjects compared to high socioeconomic level subjects,[7] but, in a study of the 2003 heat wave in Barcelona, no such association was observed.[8]

A study of the incidence of heat related deaths in St Louis during the 1980 heat wave described a sixfold risk difference between the areas of the first and the last quartiles of socio-economic level, [9] while case-crossover studies on four cities in Italy and on three Latin American cities, and a temporal study in Sao Paulo, did not find any association between the socio-economic level of the various areas considered and heat associated mortality.[10-12]

However, none of those studies took precise account of the spatial heterogeneity of heat exposure or the potentially confounding urban heat island effect.

Although indicators of the temporal association between temperature and mortality have been proposed by several authors,[13-20] few indicators of heat exposure describing the spatial heterogeneity of the mortality associated with heat waves have been constructed.[21, 22] Ozone concentration, which was particularly high during the 2003 heat wave,[23] is also suspected to play a role with respect to short-term mortality.[24] 
In that context, the objective of this study was to generate new quantitative information on the respective contributions of heat exposure and socio-economic disparities in the explanation of the excess mortality related to heat waves. An ecological analysis of the spatial heterogeneity of the August 2003 heat-wave-related mortality in France was used to address the question.

\section{MATERIAL AND METHODS}

\section{Population data}

Mainland France has a population of nearly 60 million and is administratively divided into 22 "Regions", 96 "Departements", 3,706 "Cantons" and 36,600 "Communes". The populations by Canton, age and gender were extrapolated from the 1999 census data, provided by the National Institute of Statistics and Economical Studies (INSEE), and adjusted for estimates of the marginal change in population by Departement, age and gender.

\section{Urban Unit Category (UUC)}

The urban unit category (UUC) concept developed by INSEE and based on the continuity of buildings was used to define the degree of urbanization of the Cantons. An urban unit is a group of Communes with a population of at least 2,000 in which no residence is separated from the next by more than 200 metres. If a Commune is not part of an urban unit, it is considered rural. There are five urban unit categories (UUC) of Commune: Rural (less than 2,000 people), Quasi-rural (population from 2,000 to 9,999), Quasi-urban (population from 10,000 to 99,999 ), Urban (population from 100,000 to 1,999,999) and Paris-and-suburbs (Paris Urban Unit).

\section{Mortality}

Mortality data

The mortality data were derived from the Inserm (National Institute for Medical Research) national database. The Canton of residence of each dead subject was used as the spatial location to be linked with exposure variables and socio-economic data. In this study, only subjects aged more than 55 
years were considered. They accounted for more than $95 \%$ of the excess mortality during the 2003 heat wave.[21]

\section{Mortality indicators}

A non-heat-wave-exposed reference period was defined as the months of July and August of years 2000 to 2002. In each Canton "i", the Heat Wave Mortality Ratio $\left(\mathrm{HW}-\mathrm{MR}_{\mathrm{i}}\right)$ was calculated as the ratio of the number of deaths from $3^{\text {rd }}$ to $15^{\text {th }}$ August $2003\left(\mathrm{O}_{\mathrm{i}}\right)$, to the expected number of deaths in the same Canton given its 2003 population and the age- and gender-specific mortality rates of that Canton during the reference period $\left(E_{i}\right)$.

The Standardized Excess Mortality Rate (SEMR) was used to characterize the absolute increase in mortality rate by population unit in each Canton, adjusted for the Canton population structure by age and gender. SEMR were calculated as the difference between the age- and gender-standardized mortality rates observed during the 2003 heat wave period and during the reference period.

\section{Smoothing mortality}

To map spatial variations in mortality over small spatial units, a Bayesian spatial smoothing Poisson model (BYM) was used to take into account both local over-dispersion and between-neighbour autocorrelation.[25] The neighbourhood of a given canton was defined as the cantons sharing common borders with it.

\section{Deprivation index}

The FDep99 deprivation index, previously built in order to analyse socioeconomic spatial mortality differentials over the whole country,[26] was used to characterize each Canton.

\section{Exposure to heat}

\section{Meteorological data}

Daily maximum $\left(T_{x}\right)$ and minimum $\left(T_{n}\right)$ temperatures for the months of July and August 2000 to 2003 were obtained from Météo-France. The data were derived from a grid of 4145 points (10-km step).

Daily temperature indicators were averaged over the heat wave period ( $3^{\text {rd }}$ to $15^{\text {th }}$ August 2003). Reference temperatures ( $T_{x}^{\text {ref }}$ and $T_{n}^{\text {ref }}$ ) were defined as the average of the temperatures observed 
during the reference period. From those temperatures, relative maximum $\left(T_{x}^{\text {rel }}\right)$ and minimum $\left(T_{n}^{\text {rel }}\right)$ temperatures were calculated for each Canton as the difference between the observed temperatures $\left(T_{x}\right.$ and $\left.T_{n}\right)$ and the corresponding local reference temperatures.

A recent study has identified key variables for the prediction of daily mortality rates in France as a function of daily temperature.[13] Those variables are the moving average of the mean of the minimum and maximum temperatures for the last 10 days (MA), and the number of cumulative degrees of the maximum temperature above a cut-off point over the last 10 days, set to 0 if the maximum temperature was below the cut-off point (Accum).

With regard to the averaged temperature over the whole of mainland France, the optimal cut-off point, obtained by maximization of the likelihood of the observations was $27^{\circ} \mathrm{C},[13]$ which was $2^{\circ} \mathrm{C}$ more than the average reference temperature over the whole country. In order to take into account the adaptation of population to their local climate, local cut-off points for each Canton were defined as:

- equal to $27^{\circ} \mathrm{C}$ if the maximum reference temperature of the Canton was less than or equal to $25^{\circ} \mathrm{C}$, $-2^{\circ} \mathrm{C}$ higher than the maximum reference temperature of the Canton if that temperature was greater than $25^{\circ} \mathrm{C}$.

Ozone concentration data were derived from the 10-km resolution MOCAGE chemistry-transport model developed by Météo-France.[27] The 24-hour mean ozone $\left(\mathrm{O}_{3}\right)$ concentration $\left(\mu \mathrm{g} / \mathrm{m}^{3}\right)$ from $3^{\text {rd }}$ to $15^{\text {th }}$ August 2003 was computed.

\section{Building the index of the spatial heterogeneity of heat exposure}

The spatial variation of the ratio between the mortality observed during the heat wave and that observed during the reference period in the same Canton (HW-MR) was modelled using a log linear Poisson model of the following form:

$$
\log \left[E\left(O_{i}\right)\right]=\log \left(E_{i}\right)+\alpha+\sum_{k \in S} \beta_{k} \cdot M_{k, i}
$$

In which "i" is a canton, $\mathrm{O}_{i}$ is the observed number of deaths, $E_{i}$ is the Expected number of deaths, $\mathrm{Ml}_{\mathrm{i}, \mathrm{k}}$ is one of the meteorological indicator included in the set $\mathrm{S}$, the union of the following groups of exposure indicators:

- Basic group: $T_{x}, T_{n}, T_{x} \times T_{n}$, Accum, $T_{x} \times$ Accum and MA,

- Relative temperature group: $T_{x}^{r e l}, T_{n}^{r e l}$ and $T_{x}^{r e l} \times T_{n}^{r e l}$, 
- Ozone group: $\mathrm{O}_{3}, \mathrm{O}_{3} \times \mathrm{T}_{\mathrm{x}}, \mathrm{O}_{3} \times \mathrm{T}_{\mathrm{n}}$ and $\mathrm{O}_{3} \times$ Accum.

Then, the Heat Exposure Index (HEI) was defined as the estimate of the expected value of the HW$\mathrm{MR}$, as follows:

$$
H E I_{i}=\exp \left(\hat{\alpha}+\sum_{k \in S} \hat{\beta}_{k} \cdot M_{k, i}\right),
$$

In which $\hat{\alpha}$ and the $\hat{\beta}_{k}$ are the estimated parameters deduced from the model.

\section{Sensitivity analysis}

Although the HEl used in the main analysis took into account the three groups of indicators, as a sensitivity analysis, the same associations were also calculated after excluding the relative temperature group, ozone group and both those groups from the calculation of the HEI.

The HEI was also calculated with different cut-off points defining Accum, ranging from $T_{x}^{\text {ref }}$ to $T_{x}^{\text {ref }}+$ $6^{\circ} \mathrm{C}$. Although the remaining overdispersion was not very sensitive to this choice, the $T_{x}^{\text {ref }}+2^{\circ} \mathrm{C}$ cutoff point corresponded to the lower values.

The ozone group was also calculated by considering successively the number of hours during which ozone concentration was higher than $120 \mu \mathrm{g} / \mathrm{m}^{3}$ and higher than $180 \mu \mathrm{g} / \mathrm{m}^{3}$ rather than the 24 -hour mean concentration. The results remained unchanged.

\section{Statistical software}

The main analysis, data management and mapping were done with SAS 9.1. The BYM models were computed by using the package "spdep" in R, and WinBUGS. 


\section{RESULTS}

\section{Spatial distribution of the mortality}

The spatial variability of the smoothed heat wave mortality ratios (HW-MR) was quite large, ranging from 1 to 4 (figure 1). The greatest increase in the mortality was observed in the lle-de-France Region, which includes the Paris area, and in a large band running from the north-east to the south-west of that Region.

Figure 1 here

\section{Building the Heat Exposure Index}

The scatter plot of HW-MR by heat exposure index (HEI), aggregated at the Departement level (figure 2), shows that the estimated HEI correlates quite well with the spatial variations in HW-MR. The spatial variations in $\mathrm{HEl}$ explained $68 \%$ of the extra-Poisson variability of the HW-MR, ranging from a value close to 1.0 in the Departements where the HW-MR was close to 1.0 to a value close to 3.5 in the Departements where the HW-MR was close to 3.5 .

Figure 2 here 


\section{Deprivation}

The average FDep99 index decreased progressively from high values in rural areas $(+0.49)$ to much lower values in Paris-and-suburbs (- 1.16) (table 1). In parallel the difference in averaged FDep99 index between the upper and lower quintiles of FDep99 was much larger in Paris-and-suburbs (100\%) than in rural areas (40\%). 


\section{Variations in exposure to heat with UUC and deprivation}

The average values of the heat exposure index (HEI) and the heat wave mortality ratios (HW-MR) were both close to 1.65 for the rural, quasi-rural, quasi-urban and urban areas (table 1). In contrast, the average values of the HEI and HW-MR were, on average, two-fold greater for Paris-and-suburbs (about 3.2).

As expected on the basis of the 'heat island effect', the HEI adjusted for the 22 Regions was greater in urban UUC (1.10) and Paris-and-suburbs (1.35) than in rural (1.00), quasi-rural (0.99) and quasi-urban (1.00) areas (table 1).

The local variations in HEI were positively associated with the FDep99 index in rural UUC, and negatively associated in urban UUC and Paris-and-suburbs (table 1). However, the amplitude of those associations was small.

The results were similar when the HEI were calculated without including the relative temperature or ozone concentration groups.

Table 1 Here 


\section{Variations in the association between HEI and excess mortality by deprivation}

The multiplicative interaction of the association of HW-MR with heat exposure and the FDep99 index was significantly greater than one in the quasi-urban and Paris-and-suburbs areas (table 2). The results were not modified by introducing a spatial autocorrelation structure of the observations using a BYM model. When the relative temperature and the ozone groups of meteorological variables were excluded from the HEI, the multiplicative interaction observed for the quasi-urban UUC became nonsignificant while that observed in the Paris-and-suburbs area remained unchanged.

Table 2 here

For all the UUC and both the highest and lowest quintile of the FDep99 index, the standardized excess mortality rate (SEMR) increased markedly with heat exposure (table 3). In Paris-and-suburbs, the SEMR difference between the fifth and the first quintiles of FDep99 was positive and statistically significant, for the three highest quintiles of the heat exposure index (HEI) only. This additive interaction between $\mathrm{HEl}$ and FDep99 on mortality was of high amplitude: for the three highest quintiles of the $\mathrm{HEI}$, the excess mortality for the fifth quintile of deprivation (around 20 excess deaths $/ 100,000$ people/day) was twice that of the first quintile (around 10 excess deaths/100,000 people/day).

For almost all the other UUC and quintiles of $\mathrm{HEI}$, the difference was very close to zero.

It is noteworthy that the Paris-and-suburbs UUC was simultaneously the UUC which was the most exposed to heat and the most heterogeneous in terms of deprivation (table 1). No other UUC had such a small deprived quintile and was exposed to such a high level of heat as the Cantons that were located in the last three quintiles of the heat exposure index for Paris-and-suburbs.

The difference in SEMR between the fifth and first FDep99 quintiles persisted for Paris-and- suburbs when the relative temperature and ozone concentration groups were excluded from the HEI.

Table 3 here 


\section{DISCUSSION}

A heat exposure index was defined in order to describe the geographic heterogeneity of the excess mortality observed during the August 2003 heat wave in France on the Canton scale (3706 spatial units over the whole country).

The heat exposure index explained $68 \%$ of the extra-Poisson spatial variability of the heat wave mortality ratios (HW-MR) by Canton during the heat wave. It was much greater in the most urbanized areas. This finding reflected both an urban heat island effect and the fact that the most urbanized French Region, which includes not only Paris but also less densely urbanized Cantons in the Paris area, was the most exposed to the heat wave.

For the three most exposed quintiles in the Paris area, excess mortality rates from $3^{\text {rd }}$ to $15^{\text {th }}$ August 2003 were two-fold higher in the most deprived Cantons than in the least deprived Cantons. No such additive interaction between heat exposure and deprivation was observed for the other urban unit categories, which were less exposed to heat and less heterogeneous in terms of deprivation.

\section{Heat Exposure Index (HEI)}

The HEI used in this study was based on temperature and ozone exposure variables. Some studies have suggested other variables, such as the altitude gradient of temperature or synoptic air masses, for the characterization of heat exposure,[28, 29] but country-wide data are not available.

Precise evaluation of the respective contributions of temperature and ozone variables in the description of the excess mortality is clearly of interest but was not the subject of this study. From a descriptive point of view, the temperature variables used in the present study essentially explained the spatial heterogeneity of excess mortality. The HEI may be considered a reasonable estimate of exposure suitable for evaluating the spatial interaction between exposure and deprivation with respect to mortality.

Considering the place of death as that of residence may have led to erroneous estimation of exposure to heat for the subjects who died during their holidays, particularly since August is the most popular vacation period in France. However, 96\% of the deaths during the 2003 heat wave in France occurred in the victims' Region of residence. 
The urban heat island effect gave rise to a $10 \%$ increase in HEI in the urban UUC and a $35 \%$ increase in Paris-and-suburbs, compared to the more rural UUC. Those findings are not sufficient to explain the extremely high heat exposure and excess mortality observed in Paris-and-suburbs, which were also related to hot weather over all of the lle-de-France area.

Densely populated urban areas have often been reported to be the main zones at risk during heat waves [30-34] and specific measures are being taken to attenuate the risk (more green spaces, air conditioning, etc.) $[20,35]$. However, rural zones are also subject to marked heat exposure. High excess mortality occurred in all UUC during the 2003 heat wave.

\section{Variations in the association between $\mathrm{HEl}$ and excess mortality, by deprivation index}

The multiplicative and additive interaction were both considered and found significantly positive in Paris-and-suburbs. Concerning the multiplicative approach, overdispersion was taken into account and the sensitivity to the inclusion of spatial autocorrelation (BYM model) was tested. However, the additive interaction was only considered under a marginal perspective, applying a Poisson variance to the death counts. The latter choice, implying a lost in the power of the analysis, was motivated by the large instability of additive Poisson models.

This study stands at an ecological level, which implies possible fallacies for individual associations' inferences. However, meteorological and air pollution data were computed at the finest possible scale. Therefore, confounding between exposure and socioeconomic level could have occurred if mortality and socioeconomic data were considered at a finer ecological level or at an individual level.

The geographic continuity of Paris-and-suburbs, in contrast to the scattering of the other UUC throughout France, may have conferred greater homogeneity on the relationship between heat exposure and increased mortality, and greater comparability of the socio-economic situations. In order to test that possibility, each of the 9 French urban centres with a population of 500000 or more was considered separately. However, for those urban centres, no statistically significant interaction between $\mathrm{HEI}$ and FDep99 was observed for their association with increased mortality during the heat wave. The death counts, exposure levels and deprivation heterogeneities were systematically considerably less than those observed in Paris-and-suburbs. 
In conclusion, although a marked increase in mortality related to heat wave exposure was observed for all Canton deprivation levels, the results point to the most deprived populations being more vulnerable to heat waves than the least deprived populations. This is specifically the case under extreme heat exposure when the spatial heterogeneity of deprivation is marked. 


\section{Acknowledgements}

We would like to express our gratitude to the institutions that afforded us various forms of assistance in this study: INSEE and Météo-France, and to the members of those institutions with whom we worked: G. Desplanques with INSEE; J.-M. Veysseire and G. Gayraud with Météo-France. We also are very grateful to A. Mullarky for his skilful assistance in the preparation of the English version of this manuscript.

This work was financed by Inserm (French National Institute for Health and Medical Research), InVS (Institut de Veille Sanitaire) and DGS (Direction Générale de la Santé). 


\section{REFERENCES}

1. IPCC. Summary for Policymakers. Climate Change 2007: The Physical Science Basis.

Contribution of Working Group I to the Fourth Assessment Report of the Intergovernmental Panel on Climate Change. Cambridge; 2007.

2. Bessemoulin P, Bourdette N, Courtier P, Manach J. La canicule d'août 2003 en France et en Europe. La météorologie 2004;46:25-33.

3. Rey G, Jougla E, Fouillet A, Pavillon G, Bessemoulin P, Frayssinet P, et al. The impact of major heat waves on all-cause and cause-specific mortality in France from 1971 to 2003. Int Arch Occup Environ Health 2007;80(7):615-26.

4. Semenza JC, Rubin $\mathrm{CH}$, Falter KH, Selanikio JD, Flanders WD, Howe HL, et al. Heat-related deaths during the July 1995 heat wave in Chicago. N Engl J Med 1996;335(2):84-90.

5. Naughton MP, Henderson A, Mirabelli MC, Kaiser R, Wilhelm JL, Kieszak SM, et al. Heatrelated mortality during a 1999 heat wave in Chicago. Am J Prev Med 2002;22(4):221-7.

6. Vandentorren S, Bretin P, Zeghnoun A, Mandereau-Bruno L, Croisier A, Cochet C, et al. August 2003 heat wave in France: risk factors for death of elderly people living at home. Eur J Public Health 2006;16(6):583-91.

7. O'Neill MS, Zanobetti A, Schwartz J. Modifiers of the temperature and mortality association in seven US cities. Am J Epidemiol 2003;157(12):1074-82.

8. Borrell C, Mari-Dell'Olmo M, Rodriguez-Sanz M, Garcia-Olalla P, Cayla JA, Benach J, et al. Socioeconomic position and excess mortality during the heat wave of 2003 in Barcelona. Eur J Epidemiol 2006;21(9):633-40.

9. Jones TS, Liang AP, Kilbourne EM, Griffin MR, Patriarca PA, Wassilak SG, et al. Morbidity and mortality associated with the July 1980 heat wave in St Louis and Kansas City, Mo. JAMA 1982;247(24):3327-31. 
10. Stafoggia M, Forastiere F, Agostini D, Biggeri A, Bisanti L, Cadum E, et al. Vulnerability to heat-related mortality: a multicity, population-based, case-crossover analysis. Epidemiology 2006;17(3):315-23.

11. Gouveia N, Hajat S, Armstrong B. Socioeconomic differentials in the temperature-mortality relationship in Sao Paulo, Brazil. Int J Epidemiol 2003;32(3):390-7.

12. Bell ML, O'Neill MS, Ranjit N, Borja-Aburto VH, Cifuentes LA, Gouveia NC. Vulnerability to heat-related mortality in Latin America: a case-crossover study in Sao Paulo, Brazil, Santiago, Chile and Mexico City, Mexico. Int J Epidemiol 2008;37(4):796-804.

13. Fouillet A, Rey G, Jougla E, Frayssinet P, Bessemoulin P, Hémon D. A predictive model relating daily fluctuations in summer temperatures and mortality rates. BMC Public Health 2007;7:114.

14. Braga AL, Zanobetti A, Schwartz J. The time course of weather-related deaths. Epidemiology 2001;12(6):662-7.

15. Diaz J, Garcia R, Velazquez de Castro F, Hernandez E, Lopez C, Otero A. Effects of extremely hot days on people older than 65 years in Seville (Spain) from 1986 to 1997. Int J Biometeorol 2002;46(3):145-9.

16. Ballester F, Corella D, Perez-Hoyos S, Saez M, Hervas A. Mortality as a function of temperature. A study in Valencia, Spain, 1991-1993. Int J Epidemiol 1997;26(3):551-61.

17. Hajat S, Kovats RS, Atkinson RW, Haines A. Impact of hot temperatures on death in London: a time series approach. J Epidemiol Community Health 2002;56(5):367-72.

18. Kunst AE, Looman CW, Mackenbach JP. Outdoor air temperature and mortality in The Netherlands: a time-series analysis. Am J Epidemiol 1993;137(3):331-41.

19. Saez M, Sunyer J, Castellsague J, Murillo C, Anto JM. Relationship between weather temperature and mortality: a time series analysis approach in Barcelona. Int $\mathrm{J}$ Epidemiol 1995;24(3):576-82. 
20. Tan J, Kalkstein LS, Huang J, Lin S, Yin H, Shao D. An operational heat/health warning system in Shanghai. Int J Biometeorol 2004;48(3):157-62.

21. Fouillet A, Rey G, Laurent F, Pavillon G, Bellec S, Guihenneuc-Jouyaux C, et al. Excess mortality related to the August 2003 heat wave in France. Int Arch Occup Environ Health 2006;80(1):16-24.

22. Diaz J, Garcia-Herrera R, Trigo RM, Linares C, Valente MA, De Miguel JM, et al. The impact of the summer 2003 heat wave in Iberia: how should we measure it? Int J Biometeorol 2006;50(3):159-66.

23. Vautard R, Honoré C, Beekmann M, Rouil L. Simulation of ozone during the August 2003 heat wave and emission control scenarios. Atmosph Environ 2005;39:2957-2967.

24. Ito K, De Leon SF, Lippmann M. Associations between ozone and daily mortality: analysis and meta-analysis. Epidemiology 2005;16(4):446-57.

25. Besag J, York J, Mollie A. Bayesian image restoration, with two applications in spatial statistics. Ann Inst Statist Math 1991;43(1):1-59.

26. Rey G, Jougla E, Fouillet A, Hemon D. Ecological association between a deprivation index and mortality in France over the period 1997 - 2001: variations with spatial scale, degree of urbanicity, age, gender and cause of death. BMC Public Health 2009;9:33.

27. Peuch V-H, Dufour A, Martin D. La pollution, le temps et le "temps chimique". Pollution atmosphérique 2003;179:361-368.

28. Rousseau D. Analyse fine des surmortalités pendant la canicule 2003. La Météorologie 2005;51:16-22.

29. Kalkstein LS. A new approach to evaluate the impact of climate on human mortality. Environ Health Perspect 1991;96:145-50.

30. Conti S, Meli P, Minelli G, Solimini R, Toccaceli V, Vichi M, et al. Epidemiologic study of mortality during the Summer 2003 heat wave in Italy. Environ Res 2005;98(3):390-9. 
31. Katsouyanni K, Pantazopoulou A, Touloumi G, Tselepidaki I, Moustris K, Asimakopoulos D, et al. Evidence for interaction between air pollution and high temperature in the causation of excess mortality. Arch Environ Health 1993;48(4):235-42.

32. Schuman SH. Patterns of urban heat-wave deaths and implications for prevention: data from New York and St. Louis during July, 1966. Environ Res 1972;5(1):59-75.

33. Buechley RW, Van Bruggen J, Truppi LE. Heat island equals death island? Environ Res 1972;5(1):85-92.

34. Smoyer KE. Putting risk in its place: methodological considerations for investigating extreme event health risk. Soc Sci Med 1998;47(11):1809-24.

35. Palecki MA, Changnon SA, Kunkel KE. The Nature and Impacts of the July 1999 Heat Wave in the Midwestern United States: Learning from the Lessons of 1995. Bulletin of the American Meterological Society 2001;82(7):1353-1364. 
Figure 1: $\quad$ Smoothed heat wave mortality ratio (HW-MR) (BYM), by Canton France, 3rd to 15th August 2003

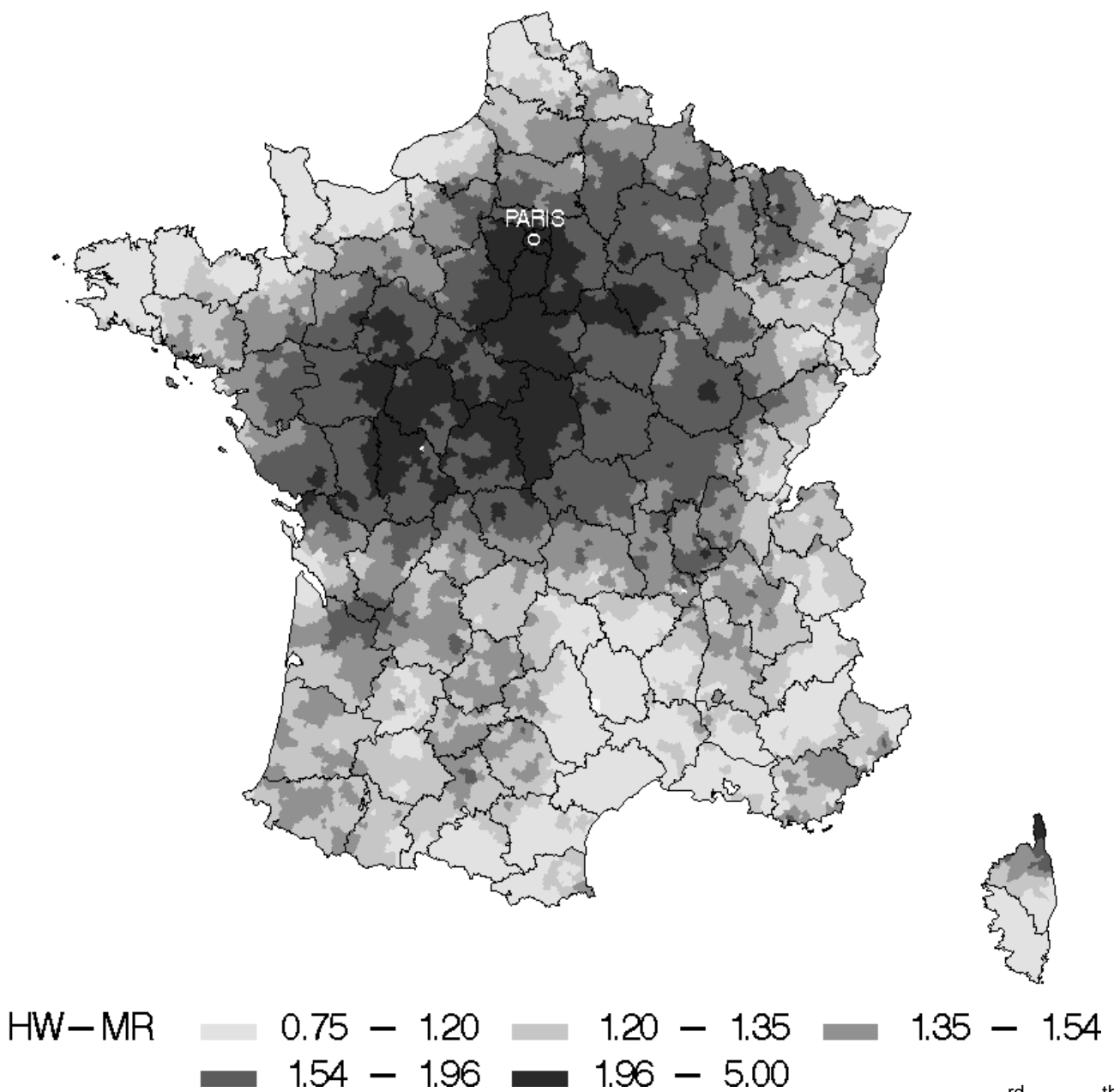

HW-MR: heat wave mortality ratio is defined as the ratio of number of deaths from $3^{\text {rd }}$ to $15^{\text {th }}$ August, 2003 , to the expected number of deaths in the same Canton given its 2003 population and the ageand gender-specific mortality rates of the Canton during the reference period (July and August of 2000-2002) 
Figure 2: $\quad$ Scatter plot of heat wave mortality ratios (HW-MR) and HEI, on the Departement scale, France, $3^{\text {rd }}$ to $15^{\text {th }}$ August, 2003

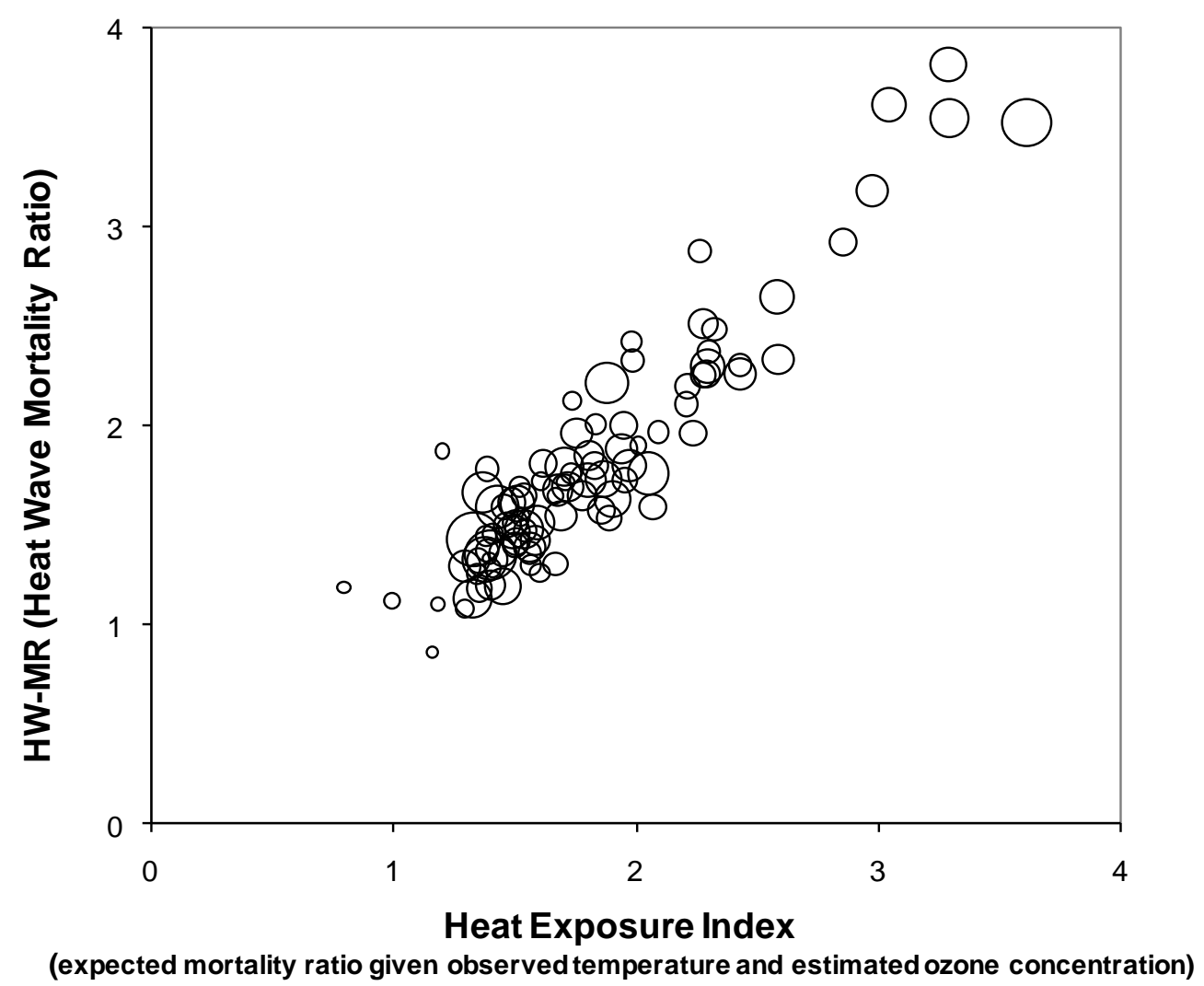

Ordinates: Observed value of the Heat Wave Mortality Ratio (HW-MR = ratio of the number of deaths observed in a given area during the 2003 heat wave to the expected value calculated from the 2003 population of the area and the age and gender specific mortality rates observed in the same area in the non-heat-wave-exposed reference period, 2000-2002.

Abscissae: Heat Exposure Index derived from the Poisson regression of the Heat Wave Mortality ratio by Canton (HW-MR), with exposure variables as covariates. It provides the estimate of the HW-MR based on the value observed for those exposure covariates. 
Table 1: Exposure differentials and heat wave mortality ratios (HW-MR) by urban unit category and their associations with the deprivation index

\begin{tabular}{|c|c|c|c|c|c|}
\hline Urban Unit Category & Rural & Quasi-rural & $\begin{array}{l}\text { Quasi- } \\
\text { urban }\end{array}$ & Urban & $\begin{array}{l}\text { Paris-and- } \\
\text { suburbs }\end{array}$ \\
\hline Number of Cantons & 1,921 & 495 & 603 & 452 & 235 \\
\hline $\begin{array}{l}\text { Population } \\
55 \text { years and over }\end{array}$ & $3,963,675$ & $1,761,097$ & $3,489,292$ & $4,478,146$ & $2,169,228$ \\
\hline \multicolumn{6}{|l|}{ Deprivation index } \\
\hline - Mean $(\% \geq \text { overall mean })^{1}$ & $0.49(66 \%)$ & $0.34(60 \%)$ & $0.32(56 \%)$ & $-0.06(37 \%)$ & $-1.16(9 \%)$ \\
\hline$-D 5-D 1^{2}$ & $40 \%$ & $51 \%$ & $48 \%$ & $62 \%$ & $100 \%$ \\
\hline \multicolumn{6}{|l|}{ Heat Wave Mortality Ratio } \\
\hline HW-MR, average value ${ }^{3}$ & 1.62 & 1.64 & 1.66 & 1.78 & 3.34 \\
\hline \multicolumn{6}{|l|}{ Heat Exposure Index ${ }^{4}$} \\
\hline - HEI, average value ${ }^{5}$ & 1.68 & 1.63 & 1.63 & 1.69 & 3.12 \\
\hline - HEI, region adjusted ${ }^{6}$ & 1.00 [Ref.] & 0.99 & 1.00 & $1.10^{*}$ & $1.35^{*}$ \\
\hline$-\mathrm{HEI}_{\mathrm{D} 5} / \mathrm{HEI}_{\mathrm{D} 1}^{7}$ & $1.08^{*}$ & 1.00 & $1.03^{*}$ & $0.96^{*}$ & $0.93^{*}$ \\
\hline
\end{tabular}

D5: fifth quintile of deprivation; D1: first quintile of deprivation

': Mean of the deprivation index, weighted by population (percentage of populations of Cantons for which deprivation is higher than or equal to the overall mean deprivation)

${ }^{2}$ : Difference between the average deprivation in the first and fifth quintiles (basis: 100 for Paris)

3: Ratio of the total number of death observed during the heat wave period (August $3^{\text {rd }}$ to $15^{\text {th }}, 2003$ ) and the total number of expected death

4: Deducted from a log-linear Poisson model relating HW-MR with temperature and ozone variables

5: Exponential of the population-weighted average of the log $\mathrm{HEI}$

${ }^{6}$ : Calculated by analysis of variance of log HEl adjusted for the 22 Regions

7: Calculated by multiplying the linear association between deprivation and log $\mathrm{HEl}$ by the difference between the average deprivation in the first and fifth quintiles, adjusted for the 22 Regions

*: Statistically different from 1 at the $5 \%$ level 
Table 2: Multiplicative variations in the association between heat exposure index (HEI) and heat wave mortality ratio (HW-MR) by deprivation

France, $3^{\text {rd }}$ to $15^{\text {th }}$ August 2003

\begin{tabular}{|c|c|c|c|c|c|}
\hline Urban Unit Category & Rural & $\begin{array}{l}\text { Quasi- } \\
\text { rural }\end{array}$ & $\begin{array}{l}\text { Quasi- } \\
\text { urban }\end{array}$ & Urban & $\begin{array}{l}\text { Paris-and- } \\
\text { suburbs }\end{array}$ \\
\hline $\begin{array}{c}\text { Ratio of the association } \\
\text { HEI - HW-MR }{ }^{1} \text { between D5 and D1 } \\
{[95 \% \mathrm{Cl}]}\end{array}$ & 1.01 & 0.97 & 1.18 & 0.99 & 1.16 \\
\hline
\end{tabular}

D5: fifth quintile of deprivation; D1: first quintile of deprivation

1: Exponential of the interaction coefficient between HEI and deprivation, multiplied by D5 - D1, derived from a Poisson model of HW-MR with over-dispersion 
Table 3: Variation in the age- and gender-standardized excess mortality rate (SEMR) between the first (D1) and the fifth (D5) quintile of deprivation, by quintile of Heat Exposure index (HEI). France, $3^{\text {rd }}$ to $15^{\text {th }}$ August 2003

\begin{tabular}{|c|c|c|c|c|c|c|}
\hline \multirow{2}{*}{$\begin{array}{l}\text { Heat exposure } \\
\text { index quintiles }\end{array}$} & \multirow{2}{*}{$\begin{array}{l}\text { Standardized } \\
\text { excess } \\
\text { mortality rates }\end{array}$} & \multicolumn{5}{|c|}{ Urban Unit Category } \\
\hline & & Rural & $\begin{array}{l}\text { Quasi- } \\
\text { rural }\end{array}$ & $\begin{array}{l}\text { Quasi- } \\
\text { urban }\end{array}$ & Urban & $\begin{array}{l}\text { Paris-and- } \\
\text { suburbs }\end{array}$ \\
\hline \multirow{3}{*}{$\begin{array}{c}\text { HEI } \\
1^{\text {st }} \text { quintile }\end{array}$} & $\operatorname{SEMR}_{\mathrm{D} 5}(1)$ & 1.4 & 2.9 & 3.4 & 1.9 & 11.7 \\
\hline & $\operatorname{SEMR}_{\mathrm{D} 1}(2)$ & 1.5 & 0.6 & 0.8 & 2.3 & 10.1 \\
\hline & (1) - (2) & -0.1 & 2.3 & 2.5 & -0.4 & 1.7 \\
\hline \multirow{3}{*}{$\begin{array}{c}\mathrm{HEI} \\
2^{\text {nd }} \text { quintile }\end{array}$} & $\operatorname{SEMR}_{\mathrm{D} 5}(1)$ & 2.8 & 4.1 & 4.2 & 4.2 & 9.7 \\
\hline & $\operatorname{SEMR}_{\mathrm{D} 1}(2)$ & 3.9 & 3.9 & 2.4 & 2.2 & 10.8 \\
\hline & $(1)-(2)$ & -1.1 & 0.2 & 1.8 & 2.0 & -1.1 \\
\hline \multirow{3}{*}{$\begin{array}{c}\text { HEI } \\
3^{\text {rd }} \text { quintile }\end{array}$} & $\operatorname{SEMR}_{\mathrm{D} 5}(1)$ & 4.9 & 4.2 & 3.5 & 3.1 & 19.0 \\
\hline & $\operatorname{SEMR}_{\mathrm{D} 1}(2)$ & 4.5 & 4.8 & 3.7 & 3.9 & 9.4 \\
\hline & $(1)-(2)$ & 0.3 & -0.7 & -0.2 & -0.8 & $9.6^{*}$ \\
\hline \multirow{3}{*}{$\begin{array}{c}\text { HEI } \\
4^{\text {th }} \text { quintile }\end{array}$} & $\operatorname{SEMR}_{\mathrm{D} 5}(1)$ & 5.6 & 4.4 & 5.2 & 9.2 & 23.0 \\
\hline & $\operatorname{SEMR}_{\mathrm{D} 1}(2)$ & 6.8 & 2.4 & 3.8 & 7.4 & 12.4 \\
\hline & $(1)-(2)$ & -1.1 & 2.0 & 1.4 & 1.8 & $10.6^{*}$ \\
\hline \multirow{3}{*}{$\begin{array}{c}\mathrm{HEI} \\
5^{\text {th }} \text { quintile }\end{array}$} & $\operatorname{SEMR}_{\mathrm{D} 5}(1)$ & 7.3 & 7.7 & 10.5 & 12.4 & 22.3 \\
\hline & $\operatorname{SEMR}_{\mathrm{D} 1}(2)$ & 7.1 & 9.4 & 8.4 & 7.1 & 12.0 \\
\hline & $(1)-(2)$ & 0.1 & -1.8 & 2.1 & $5.3^{*}$ & $10.3^{*}$ \\
\hline
\end{tabular}

D5: fifth quintile of deprivation; D1: first quintile of deprivation

SEMR: standardized excess mortality rate (number of excess deaths $/ 100,000 /$ day) standardized by age and gender

*: The difference between the SEMR of the Cantons of the most deprived quintile and the SEMR of the Cantons of the least deprived quintile is statistically different from 0 at the $5 \%$ level 